\title{
Productivity Analysis of the General Electric Company of Libya
}

\author{
Abdulbaset Frefer ${ }^{1}$, Rabia Emhamed Almamlook ${ }^{2}$, Mohamed Suwayd ${ }^{3}$ \\ ${ }^{1}$ Mechanical and Industrial Engineering Department, University of Tripoli, Tripoli, Libya \\ ${ }^{2}$ Department of Industrial, Manufacturing Engineering and Engineer Management, Western Michigan University, Kalamazoo, USA \\ ${ }^{3}$ Engineering Management Department, University of Tripoli, Tripoli, Libya
}

Email address:

drfrefer@hotmail.com (A. Frefer), rabiaemhamedm.almamlook@wnmich.edu (R. E. Almamlook), mohamedsuwayed@yahoo.com (M. Suwayd)

\section{To cite this article:}

Abdulbaset Frefer, Rabia Emhamed Almamlook, Mohamed Suwayd. Productivity Analysis of the General Electric Company of Libya. American Journal of Management Science and Engineering. Vol. 2, No. 6, 2017, pp. 192-198. doi: 10.11648/j.ajmse.20170206.15

Received: November 18, 2017; Accepted: November 29, 2017; Published: January 2, 2018

\begin{abstract}
In this study, the current situation of the General Electric Company of Libya (GECOL) was assessed by measuring the total and partial service productivity from 2006 to 2014, using a proposed measurement model, which was constructed based on a well-known model adopted for analysis of productivity which satisfies the basic productivity concept. Two phases were used in this study to measure the company's productivity. In phase one, productivity was measured using the outputs data based on the electricity delivered (excluding) the technical losses in order to obtain the accurate productivity of the company. In phase two; an attempt was made to find the actual output, by using the electricity delivered including the technical losses to obtain the productivity that represents the true performance. The results showed that there was a decline in the productivity of the company in all years of the study period and that the company's overall performance during the study period was generally poor.
\end{abstract}

Keywords: General Electric Company of Libya, Productivity Measurement, Total and Partial Productivity

\section{Introduction}

Performance measurement is a topic that has received considerable attention during the last decades and many definitions have been used. In 1980, The Government Accounting Office US (GAO) defined performance measurement as an assessment of an organization's performance, including the measures of productivity, which quantifies the output and input of an organization and expresses the two as a ratio [1]. Effectiveness that determines the relationship of an organization's output to what an organization is intended to accomplish. Productivity measurement is a well-known Total Productivity (TP) and Partial Productivity (PP) models were proposed to measure and compare productivity performance of the GECOL from 2006 to 2014.

There are two models that can be included, which is based on the value of production. First model is based on the value of the revenue obtained from selling goods or services [2, 20 and 21]. The second model that is Product Oriented model, one of the most common models that follow this category is Sumanth Total Productivity model [22]. Sumanth model is considered as a major milestone in the field of productivity measurement [16].

Over the years there have been many studies conducted to evaluate the productivity performance of the electricity industry, Early Australian productivity studies focused on the state electricity sector. For example, the Industries Assistance Commission [5] estimated the total productivity for three states for the period of 1954 to 1987, where the study conducted by the Bureau of Industry Economics and Productivity Commission [6] estimated TP for Australian electricity supply. The major electricity distribution TFP studies undertaken in Australia have been a series of studies using index number method [7 and 8]. Study applied DEA to assess the productivity of electricity distribution companies in Peru [9]. Another study assessed the productivity of the Brazilian electricity distribution sector [10].

Hattori et al compared the performance of electricity distribution systems in the UK [11]. Where Hjalmar son et al estimated the productivity growth in electricity retail 
distribution in Sweden [12]. Forslund et al. assessed the productivity development of Norwegian electricity distribution utilities [13]. Von Hirschhausen et al used DEA and SFA to assess the efficiency of electricity distribution companies in Germany [14]. Because of the increasing demand for the electrical power needed for economic and social growth and to provide electricity to the consumer in sufficient quantities and high quality.

The situation in Libya is completely different, since the electricity sector is owned by the state and the General Electric Company (GECOL) is responsible for the operation and maintenance, because of these obstacles, it was not possible to measure the rate of growth in productivity of the company, and instead, total productivity index model was used to measure the changes in the company's productivity during the study period, since productivity is a relative measure, and to be meaningful or useful it must be compared to something. According to Davis, a number productivity is defined as the ratio between tangible outputs and total tangible inputs, and productivity is the ratio between real output and the use of real factors or inputs [3 and 4].

\section{The Objective of This Study}

The objectives of this study were to estimate the Partial productivity and the TP of the General Electric Company of Libya and use the results to evaluate the current situation of the General Electric Company of Libya, by using GECOL Proposed models, which constructed based on the Sumanth Total productivity model $[15$ and 16]. Productivity Accounting model by Davis [2] and Total Factor Productivity Index Method/ Fisher Index model [17].

\section{Measure of Productivity for GECOL}

The General Electricity Company of Libya (GECOL) is a $100 \%$ state owned company, which was established in 1984. GECOL is responsible for all electricity sectors in Libya; Including, Generation, Transmission, Distribution, and Customer Services. Electrical Energy is generated by thirteen power plants including Gas Power Plants, Steam Power Plants, and Combined Cycle Power Plants [18]. The Libyan Transmission Grid covers a wide geographical area from the Egyptian to the Tunisian boarders $(\sim 2000 \mathrm{~km})$, and from the Mediterranean coast to the southern side $(\sim 900 \mathrm{~km})$. The Transmission Grid Delivers Electricity to $\sim 99 \%$ of Libyan areas. The company depends mainly on national cadres, the number of employees by the end of the year 2014 about 40,000 across various specialties. Due to the abnormal circumstances of (2011 \& 2012), GECOL faced a shortage in the energy production process, which led to 1200-megawatt load shedding ( $20 \%$ of total peak load). [18].

For identification of GECOL productivity, input and output are shown in the flowchart in Figure 1

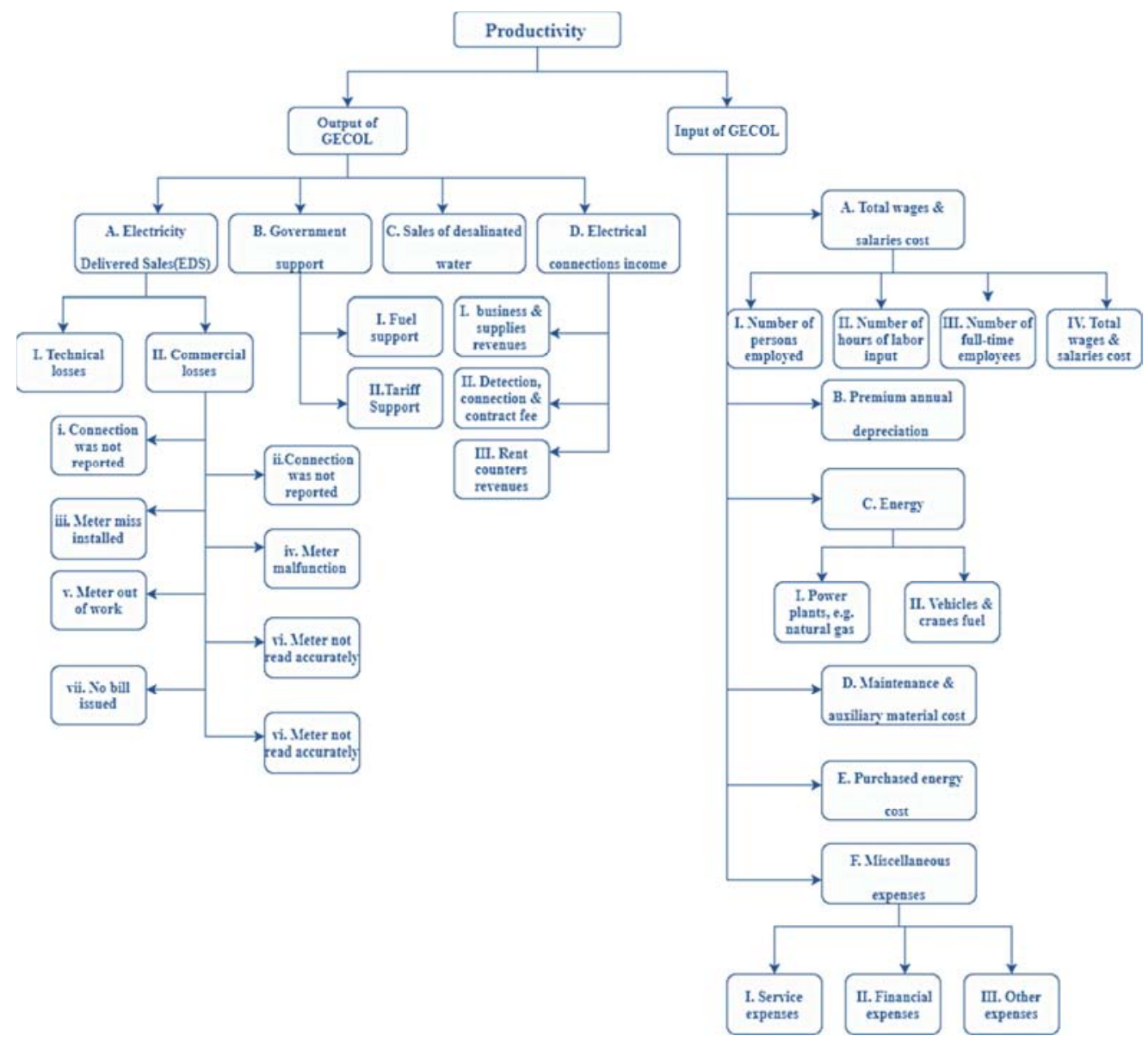

Figure 1. Identification of productivity of GECOL. 


\section{Research Approach and Methodology}

Methodology presents the roadmap to continue the scientific investigation. It can be defined; [19] as "the general approach the researcher takes in carrying out the research project". In this study, data was obtained by the General Electric Company of Libya (GECOL). To determine the methodology that was be applied for calculating the productivity of the GECOL and for best results, the company's productivity was measured in two phases; in phase one, productivity was measured using the total output based on the electricity delivered sales, excluding the technical losses in order to obtain the productivity that represents the true financial realities of the company. However, in phase two, an attempt was made to find the actual output, by using the electricity delivered sales, including the technical losses in order to obtain the productivity that represents the true performance. The input and output information in this study was from 2006 to 2014, where the year 2011 was not included due to data limitations and of the failure to obtain the necessary input and output.

\subsection{The GECOL Proposed Models}

Total Productivity (TP) and Partial Productivity (PP) models were proposed to measure and compare productivity performance of the GECOL from 2006 to 2014. There are two models that can be included, which is based on the value of production. The researchers adopted the Sumanth model and Davis model to measure the total and partial productivity of GECOL because both models are the most appropriate models to the understudy conditions, a number of input and output of the company and the type of data obtained. The situation in Libya is completely different, since the electricity sector is owned by the state and the General Electric Company (GECOL) is responsible for the operation and maintenance, because of these obstacles, it was not possible to measure the rate of growth in productivity of the company, and instead, total productivity index model was used to measure the changes in the company's productivity during the study period, since productivity is a relative measure, and to be meaningful or useful it must be compared to something [15].

\subsection{Implementation of the Proposed Models}

Based on the previous discussion, the proposed models to measure the total and partial productivity and productivity change of GECOL is: [15]

$$
\begin{gathered}
\text { Total Productivity }=\frac{\text { Total Tangible Output }}{\text { Total Tangible Input }} \\
\text { Partial Productivity }=\frac{\text { Total Tangible Output }}{\text { One Class Of Input Monetary Value }} \\
\text { PTI }=\mathrm{PTt} \div(\mathrm{PTt}-1) \\
\text { PPI }=\mathrm{PPt} \div(\mathrm{PPt}-1)
\end{gathered}
$$

Where: Total Tangible Output $=$ The summation of all output components monetary values, Total Tangible

Input $=$ The summation of all Input components monetary values, $\mathrm{PTI}=$ Total productivity index,

$\mathrm{PT}_{\mathrm{t}}=$ Total productivity at time $(\mathrm{t}), \mathrm{PT}_{\mathrm{t}-1}=$ Total productivity at base period, $\mathrm{PPI}=$ Partial productivity index,

$\mathrm{PP}_{\mathrm{t}}=$ Partial productivity at time $\mathrm{t}$ and $\mathrm{PP}_{\mathrm{t}-1}=$ Partial productivity at base period.

The factors that constitute the total input parameters for measuring productivity of GECOL are: Total

Wages and Salaries Cost (TWC), Premium Annual Depreciation (PAD), Energy input (E), Maintenance and

Auxiliary Materials Expenses. (MAE), Purchased Energy Costs (PEC), Miscellaneous Expenses Input (ME), $M E$ consists of the following:

$$
\mathrm{ME}=\mathrm{SE}+\mathrm{FE}+\mathrm{OE}
$$

Where: $\mathrm{SE}=$ Service Expenses, $\mathrm{FE}=$ Financial Expenses and $\mathrm{OE}=$ Other Expenses.

In order to measure or calculate the electricity delivered sales, a model was developed by the researchers:

$$
\begin{aligned}
& \text { ESVC }=\text { APCC } * \text { PETC } \\
& \text { EDS }=\sum_{i=1}^{M} \text { ESVC } \mathrm{i}
\end{aligned}
$$

Where:

The factors that constitute the total output parameters for measuring productivity of GECOL are: Electric Sales Volume for Each Customer Category (ESVC), Amount of Power Consumed for Each Customer Category (APCC), Price of Electricity Tariff for Each Customer Category (PETC), Electricity Delivered Sales (EDS), Government Support (GS), Sales of Desalinated Water (SDW), Electrical Connections Income (ECI), Other Income (OI).

OI consists of the following:

$$
\begin{gathered}
\mathrm{OI}=\mathrm{MI}+\mathrm{IPY} \\
\mathrm{ECI}=\mathrm{BSR}+\mathrm{DCC}+\mathrm{RCR}
\end{gathered}
$$

Based on the results of identifying the components of the company's output and input, which obtained in the previews step, the Output of GECOL can be expressed by the following equations:

$$
\mathrm{TO}=\mathrm{EDS}+\mathrm{GS}+\mathrm{SDW}+\mathrm{ECI}+\mathrm{OI}
$$

The Input of GECOL can be expressed in the following equations:

$$
\mathrm{TI}=\mathrm{TWC}+\mathrm{PAD}+\mathrm{E}+\mathrm{MAE}+\mathrm{PEC}+\mathrm{ME}
$$

Substituting these equations (10) and (11) back into proposed model, this study gets the GECOL Total and Partial Productivity measurement model, which used in this study to measure the total and partial productivity and the productivity changes of GECOL during the period from 2006 to 2014. 


$$
\begin{gathered}
\mathrm{TP}=\frac{\mathrm{EDS}+\mathrm{GS}+\mathrm{SDW}+\mathrm{ECI}+\mathrm{OI}}{\mathrm{TWC}+\mathrm{PAD}+\mathrm{E}+\mathrm{MAE}+\mathrm{PEC}+\mathrm{ME}} \\
\mathrm{pp}=\frac{\mathrm{TO}}{\mathrm{Ii}}
\end{gathered}
$$

Where: $\mathrm{TP}=$ Total Productivity, $\mathrm{PP}=$ Partial Productivity, $\mathrm{TO}=$ Total Tangible Output $=$ The summation of all output components monetary values, TI $=$ Total Tangible Input $=$ The summation of all Input components monetary values, Ii = One Class of Input Monetary Value, EDS = Electricity Delivered Sales, GS = Government Support, SDW $=$ Sales of Desalinated Water, ECI = Electrical Connections Income, OI = Other Income, TWC = Total Wages and Salaries Cost, PAD = Premium Annual Depreciation, $\mathrm{E}=$ Energy, $\mathrm{MAE}=$ Maintenance and Auxiliary Materials Expenses, PEC = Purchased Energy costs and $\mathrm{ME}=$ Miscellaneous expenses.

\section{Results and Discussion}

Two phases were used in this study to measure the company's productivity. In phase one, productivity was measured using the outputs data based on the electricity delivered the technical losses in order to obtain the accurate productivity of the company.

Figure 2 shows total productivity, total output, and total input indexes. Relative level of total productivity (TP) remains the same for the years 2006, 2007 and 2008, with a slight increase in 2007, after that it shows upward trend by 14 percent in 2009 comparing with 2008, before falling by 7 percent in 2010, and in 2012, TP increased by 15 percent, then rapid decline by 25 percent.

To understand what has caused the change in total productivity, it was essential to examine the partial productivity indexes. In figures 3 the six partial productivities were presented, which calculated using the partial productivity model. Figure 3 displays that during the period from 2006 to 2008 the total productivity remains same because the amount of the increase in the value of the inputs and outputs was approximately equal. The slight increase in productivity in 2007, was the result of the increase in outputs by 19 percent. In 2009 all partial productivities except energy productivity are increased as shown in figure 3, because of increase in electricity delivered sales and the government support revenues.

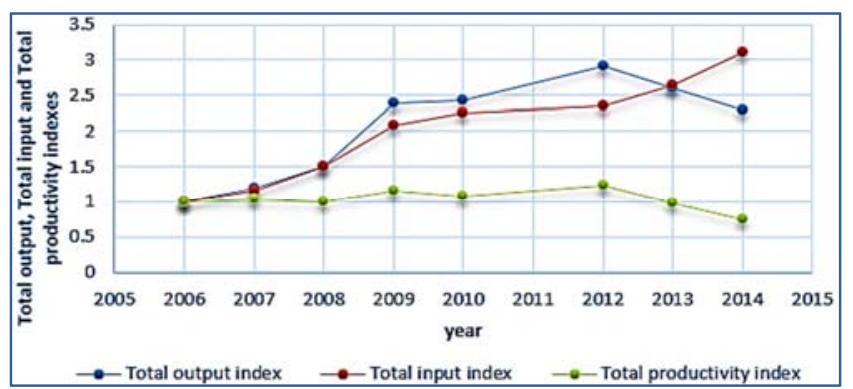

Figure 2. Total Productivity Index, Total Output Index and Total Input Indexes.

During 2012, and despite a decline in most of the output component due to the increase in the government support revenue about three times, and this led to increasing in total productivity by 15 percent. For the years 2013, 2014 decline in most of the partial productivities, a rapid decline in outputs by $11 \& 12$ percent respectively. The main cause of this rise was an increase in total wages and salaries cost by 16 percent and increase in purchased energy cost from $8,848,223 \mathrm{LD}$ to $334,210,893 \mathrm{LD}$, this led to a decline in productivity by 25.5 percent in 2013 and by another 33 percent through to 2014 .

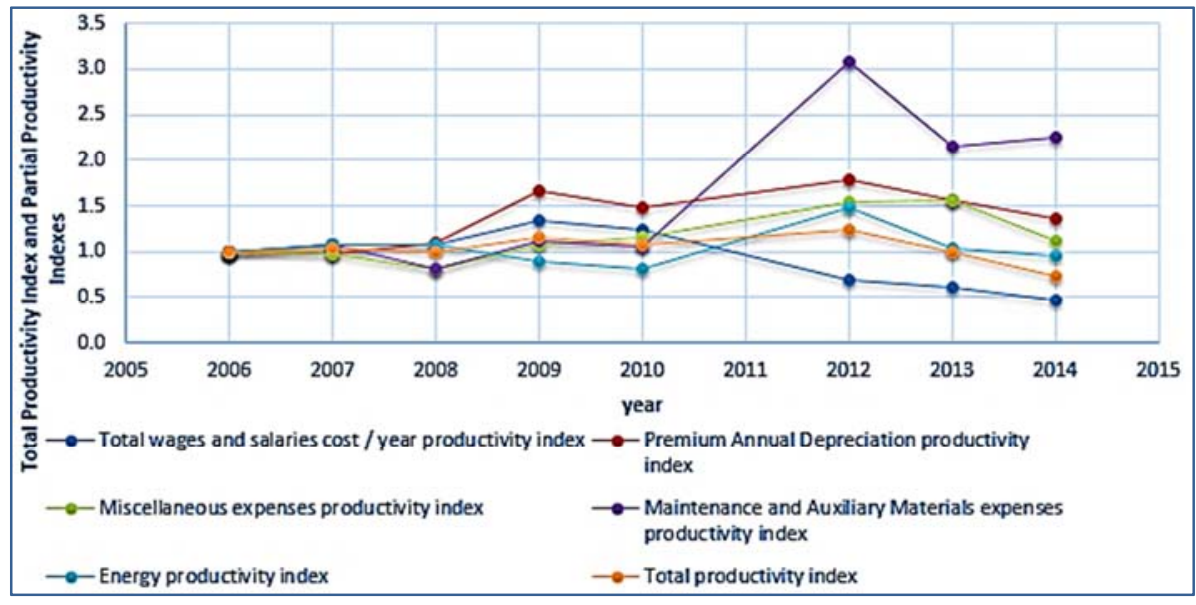

Figure 3. Total Productivity Index and Partial Productivity Indexes.

Moreover, in phase two; an attempt was made to find the actual output, by using the electricity delivered including the technical losses to obtain the productivity that represents the true performance. Figure 4, shows that a fluctuation in productivity index throughout the study period, and the highest productivity value was 1.19 in 2012 . Relative level of total productivity shows upward trend by 2.9 percent in 2007 , after that fell by 15 percent in 2008 , before remaining same for the years 2008, 2009 and 2010, with a slight increase in 2009 , in 2012 TP rapidly increased by 25 percent, then declined by 8 percent in 2013 and by another 14 percent through 2014. 


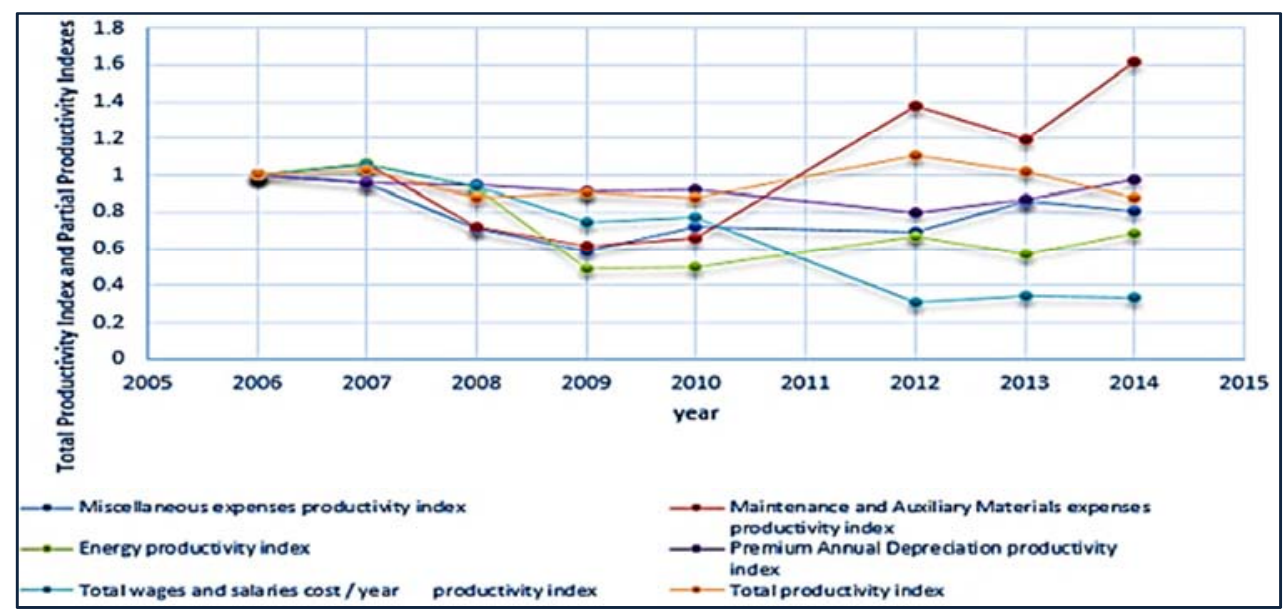

Figure 4. Total Productivity Index and Partial Productivity Indexes.

Therefore, to recognize what has caused the change in total productivity, it should be studied partial productivity to phase two. Figures 4 display an increase in total productivity by 2.9 percent in 2007. The productivity rise was the result of an increase in outputs value by 17.9 percent. In 2008, all partial productivities, except purchased energy productivity are declined as shown in Figures 4, which means that the purchased energy cost decreased, and all the rest of inputs are increased, the value of outputs increased by 11.2 percent, because of the increase in electricity delivered sales and the other income revenues, and the value of inputs increased by 30.9 percent, this led to a decline in total productivity by 15 percent.

During 2012, energy productivity and MAE productivity are increased, all the rest of partial productivities

are declined, despite a decline in most of the outputs, the value of outputs increased by 31.1 percent, due to the increase in the government support revenue about three times, and this led to rapidly increase in total productivity by 25.8 percent. For the years 2013, 2014, decline in total productivity. In 2013, the increase in inputs was greater than the increase in outputs, this leads to the decline in total productivity by 8 percent. During 2014, outputs and input value increased, the main cause of this rise was an increase in total wages and salaries cost by 15.7 percent and increase in purchased energy cost about two and this led to a decline in productivity by 14 percent.

By comparing the productivity values that were obtained in phases, one and two as can be seen in Figure 5. It can observe an improvement in productivity of the company in all the years of the study, at a rate ranging from 13 percent in 2009 to 71 percent in 2014 . The improvement of productivity values was resulted by using total electricity consumed, which include the commercial losses values in the measurement of actual total outputs.

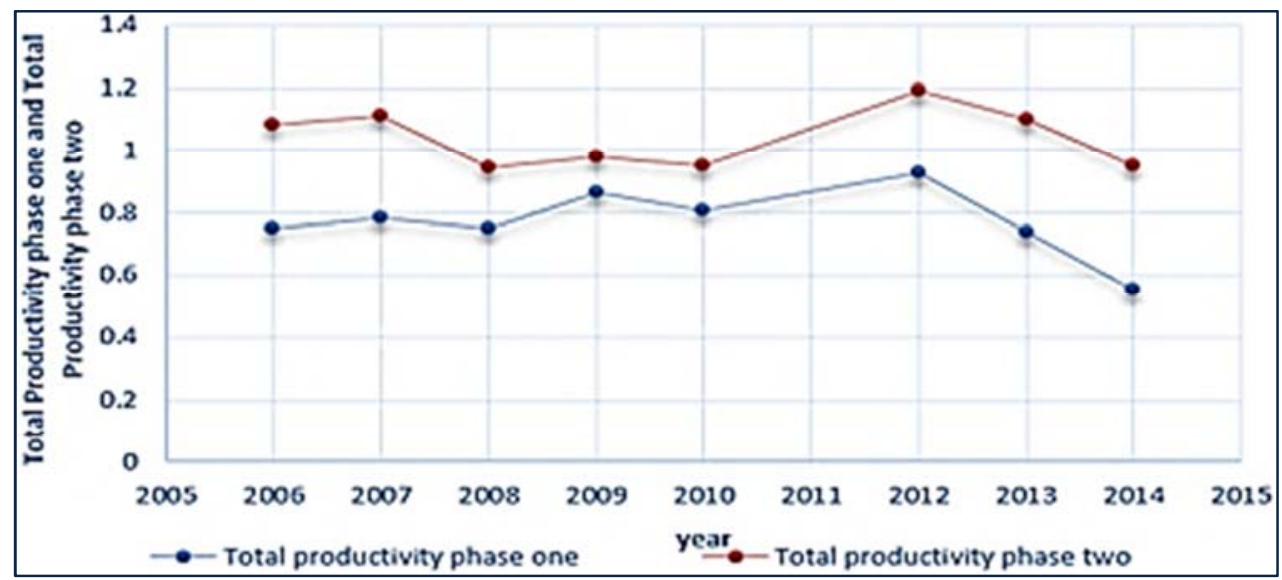

Figures 5. Total Productivity of phases, one and two.

There are several criteria for the evaluation of any measurement system by measurement theory. The appropriateness of the proposed productivity model is evaluated with the help of the following six criteria. These criteria are: Validity, Completeness, Comparability, Inclusiveness, Timeliness, Cost - effectiveness. [15, 23 and 24].

\section{Conclusion}

This study contributes towards new insights on the productivity level of the General Electric Company in Libya (GECOL). Productivity and performance analysis was 
estimated for the GECOL from 2006 to 2014. The process of constructing productivity measurement model to a company depends on the possibility of accurate identification of all inputs and outputs in the form of financial value. Thus, the first step in this study was to identify all the inputs and outputs of the GECOL and use them to apply the proposed models. The proposed model for the productivity measurement of the GECOL is simple and qualifies to comply with the above referred six criteria. It can also be used to detect the problem areas of poor productivity performance of the electricity industry. Indeed, one can conclude that the study has achieved its targeted objectives mentioned at the beginning of the study. It can conclude that productivity was declined in all the years of the study period which indicate a lack of efficient utilization of the resources available to the company. Also, the company's revenues depend mainly on the government support, where the share of the government support in the total output and continues to rise until it during the period from 2009 to 2014. Commercial losses led to declining in the company's productivity, and when these losses are included in the productivity calculation, there was an improvement in the productivity of the company in all years of the study. Because of increasing in the total wages, salaries expenses, and purchased energy costs during the period from 2012 to 2014 which led to the increase in the total inputs. The results presented that there was a decline in the productivity of the company in all years of the study period and that the company's overall performance during the study period was generally poor. Overall, the company's overall performance during the study period is generally poor, this may be attributed to the incompetency of the company's management in managing resources and facilities available to the company.

\section{Acknowledgements}

This work was supported by General Electric Company of Libya (GECOL), all authors wish to thank all employees and managers for their assistance in data collection.

\section{References}

[1] U. S. General Accounting Office, Closer Controls and Better Data Could Improve Antitrust Enforcement, Feb. 29, 1980.

[2] Davis, H. S., Productivity Accounting, University of Pennsylvania Press, Philadelphia, 1955.

[3] Siegel I. H., Measurement of Company Productivity, National Center for Productivity and Quality of Working Life, 1976, pp. 15-26.

[4] Timbergen, J., Econometric business cycle research, Review of Economic Studies, 1940.

[5] IAC (Industries Assistance Commission), Inquiry into Government (Non-Tax) Charges, Volume 4 Studies - Public Rail Freight, Electricity and Workers Compensation Arrangements, Report no. 422, September 1989, AGPS, Canberra.
[6] BIE/PC (Bureau of Industry Economics/Productivity Commission), Electricity International Benchmarking, Report 96/16, September, AGPS, Canberra, 1996.

[7] Lawrence, Denis, Benchmarking Comparison of Energex Ltd and 9 Other Australian Electricity Distributors, Report by Tasman Asia Pacific for Queensland Competition Authority, Canberra, 2000.

[8] Lawrence, D., Diewert, E., Fallon, J., and Kain, J., Economic Insights, Electricity Distribution Industry Productivity Analysis: 1996-2008, A Report Submitted to the Commerce Commission, Canberra, and 2009b.

[9] Perez R. and Tovar B., Measuring Efficiency and Productivity Change (PTF) in The Peruvian Electricity Distribution Companies after Reforms, Energy Policy, 2009, vol. 37, no. 6, pp. 2249-2261.

[10] Real F. J. R., Tover B., Iooty M., Almeida E. F. D., and Pinto H. Q., The Evolution and Main Determinants of Productivity in Brazilian electricity Distribution 1998-2005: An Empirical Analysis, Energy Economics, 2009, vol. 31, no. 2.

[11] Hattori, T., Jamasb, T., and Pollitt, M., Electricity Distribution in the UK and Japan: A Comparative Efficiency Analysis 1985-1998, Energy Journal, 2005, vol. 26, no. 2, pp. 23-47.

[12] Hjalmarsson, L., and Veiderpass, A., Productivity in Swedish Electricity Retail Distribution, Scandinavian Journal of Economics, 1992, vol. 94, pp. 193-205.

[13] Forsund F. R. and Kittelsen S. A. C., Productivity development of Norwegian Electricity Distribution Utilities, Resource and Energy Economic, 1998, vol. 20 no. 3, pp. 207224.

[14] Von Hirschhausen., Christian R. and Cullmann, A., Efficiency Analysis of German Electricity Distribution Utilities: NonParametric and Parametric Tests, Dresden Discussion Paper Series in Economics 06/05, Dresden University of Technology, Faculty of Business and Economics, Department of Economics, 2005.

[15] Suwayd, M. A., Productivity Performance Analysis of the General Electric Company of Libya, MSc Thesis, Engineering College, University of Tripoli, Spring 2017.

[16] Sumanth, D. J., Productivity Engineering and Management, New York, McGraw-Hill, 1984.

[17] Fisher I, the Making of Index Numbers, Boston: HoughtonMifflin, 1922. General Electricity Company of Libya, Status of the Libyan Power System and Its Future Plans, MEDELEC 21st Annual Meeting, Tripoli - Libya, April 4 the 2013 .

[18] Leedy, P. and 68 Ormrod, J., Practical research: Planning and design (7th ed.), Upper Saddle River, NJ: Merrill Prentice Hall, Thousand Oaks: SAGE Publications, 2001.

[19] Kendrick, J. W., and D. Creamer, Measuring Company Productivity: Handbook with Case Studies, Studies in Business Economics, National Industrial Conference Board, New York, 1965.

[20] Craig, C.; Harris, R., Total Productivity Measurement at the Firm Level, Sloan Management Review, 1973, pp. 13-28.

[21] Alshekh, A., Productivity Planning (1st Edition.), Alezdehar Printing, Misurata, 2008, (Translated From Arabic Edition). 
[22] M. A. Wazed and Shamsuddin Ahmed, Multifactor Productivity Measurements Model (MFPMM) as Effectual Performance Measures in Manufacturing, Australian Journal of Basic and Applied Sciences, 2008, vol. 2, no. 4, pp. 987996.
[23] R. Gupta and S. K. Dey, Development of a Productivity Measurement Model for Tea Industry, ARPN Journal of Engineering and Applied Sciences, 2010, vol. 5, no. 12, pp. 16-25. 